\title{
An Experimental Webquest-based Teaching Platform for Network Interconnection Course
}

\author{
JIANG Zhongyun
}

\begin{abstract}
Traditional web-learning solution was designed for individual teaching unit and without generalized support platform. This drawback give rising to a series of difficulties of teaching resources management, reuse and integration. By analyzing the teaching requirements of network interconnection course, by means of constructivist learning theory, on the basis of the web-based teaching resources library, a webquest-based teaching platform for network interconnection course was proposed in this paper. The platform is designed to resolute the limitations of traditional teaching model, and it puts forward a blended learning model which integrates both classroom and online learning model to improve the learning opportunities and motivation.
\end{abstract}

Index Terms-Webquest; Blended Learning; Network Interconnection; Teaching Platform

\section{INTRODUCTION}

Present, including government, military, research institutions, enterprises and other organizations, various social sectors requires a lot of network engineering personnel. With the rapidly increasing demand in network engineering talents, Universities and colleges need to adapt to the times, train high-quality network talent to meet the needs of network engineering professionals, which has become an urgent and important strategic task [1].

However, the teaching process of the traditional teacher-centered teaching model is dogmatic and single. Long in a passive position, learners are lack of autonomous and independent sense of learning, not to mention the training of innovation and practical ability. The traditional teaching model is not conducive to train the personality of students and reflect the dominant position of students.

Reforming the traditional teacher-centered model of teaching and setting up a new teaching model, it has become a topic of common concern. In the new teaching model, teachers can play a leading role but also fully embodies the main role of students. The new teaching model can achieve the collaboration and communication between teachers and students, and between students. Constructivism-based webquest teaching model is a relatively new science teaching model. Using webquest to carry out inquiry teaching, it can make up for the lack of traditional classroom teaching, and has an active effect to train the exploring ability, independent research and development capabilities, innovative thinking, and Pioneering knowledge level of students[2,3].

In this paper, with the author's own teaching practice, a

Manuscript received August 1, 2011; revised August 15, 2011.

JIANG Zhongyun is with the Dapartment of Information Technology, Shanghai Jianqiao College, China. (zoejiang3@163.com) webquest-based teaching method was applied in the network interconnection course. The effective integration of classroom and online learning model, reach on the training objectives of network engineering and technical personnel.

\section{Webquest-BAsed TeAching Model fOR Network INTERCONNECTION COURSE}

\section{A. The teaching requirements of network interconnection course}

Network interconnection course is the main course of network engineering major. This course is a comprehensive curriculum, which containing the knowledge of network principle, network interconnection, network management and network security and other disciplines. The main feature of this course is the theory and operating related closely, involving a large number of content, technology updates fast. Teaching objects are network engineering undergraduate senior. The students have good experimental and theoretical basis, and their ability to accept is strong. Planning and setting up an efficient and feasible computer network is an important part of future work for network engineering graduates. By studying "network interconnection" course, students should have the following capabilities, such as:

- Basic network interconnection capability

- Ability to digest

- $\quad$ Practical ability

- Network configuration experience

- Network planning and design experience

- Ability of unity and cooperation

\section{B. Blended learning theory}

In the international community of educational technology, the concept of blended learning was proposed which was considered a change of educational thought and teaching ideas [4]. As one of the trends of the future development of educational technology, blended learning is a teaching strategy which integrated using the different learning theories, different techniques and different application methods and ways to implement the teaching. Blended learning is a teaching model which integrates organically the advantages of both classroom learning and online learning. Blended learning model can use multimedia technology to carry out classroom teaching, and can use network platforms to carry out supplementary teaching activities, shown as in Figure 1. Blended learning can rationally select and assemble all learning elements, so that the learning is the most efficient and the learning the lowest cost. 


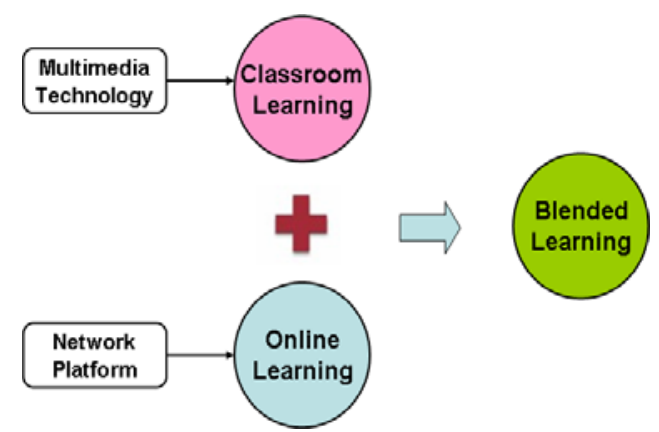

Fig.1. Blended Learning Model

Blended Teaching is a two-centered teaching model which guided by teacher on the basis of Internet, it really changes the teachers teaching and students learning. Learning through exploration can develop good thinking ability, information skills, problem awareness, cooperative learning, innovation, scientific method, as well as a vivid personality development of students.

\section{Webquest teaching theory}

Constructivist learning theory holds that knowledge is not obtained by teachers teaching, but by learners constructing knowledge. Learners acquire knowledge by learning in a certain situation, with the help of others including teachers and learning partners, and with the necessary learning materials [4]. Webquest is essentially a practice performance of constructivist learning theory in network learning process. In the network environment, guided by teachers, using network resources, driven by webquest, learners can independently carry out learning activities such as construction, exploration and research. Webquest orients the learner to the task ahead and grabs their interest, drawing them into the project.

A webquest is an inquiry-oriented activity in which some or all of the information that learners interact with comes from resources on the internet [5]. There are at least two levels of webquests that should be distinguished from one another, short-term webquest and longer-term webquest. The instructional goal of a short-term webquest is knowledge acquisition and integration. At the end of a short term webquest, a learner will have grappled with a significant amount of new information and made sense of it. A short-term webquest is designed to be completed in one to three class periods. The instructional goal of a longer-term webquest is extending and refining knowledge. After completing a longer term Webquest, a learner would have analyzed a body of knowledge deeply, transformed it in some way, and demonstrated an understanding of the material by creating something that others can respond to, on or off-line. A longer-term webquest will typically take between one week and a month in a classroom setting.

Webquests of either short or long duration are deliberately designed to make the best use of a learner's time. There is questionable educational benefit in having learners surfing the net without a clear task in mind, and most schools must ration student connect time severely. To achieve that efficiency and clarity of purpose, webquest should contain the following steps: Introduction, Task, Process, Resources, Evaluation, and Conclusion [5].
- An introduction that sets the stage and provides some background information.

- The task focuses learners on what they are going to do.

- A description of the process the learners should go through in accomplishing the task. The process should be broken out into clearly described steps.

- A set of resources are needed to complete the task. Many (though not necessarily all) of the resources are embedded in the webquest document itself as anchors pointing to information on the World Wide Web.

- The evaluation section describes the criteria needed to meet performance and content standards. The best assessment tool is a rubric.

- A conclusion that brings closure to the quest, reminds the learners about what they've learned, and perhaps encourages them to extend the experience into other domains.

\section{Webquest-based teaching model of network interconnection course}

By analyzing the characteristics of webquest teaching theory, combined with the teaching requirement of network interconnection course, a new webquest-based teaching model for network interconnection course was proposed, shown as in Figure 1.

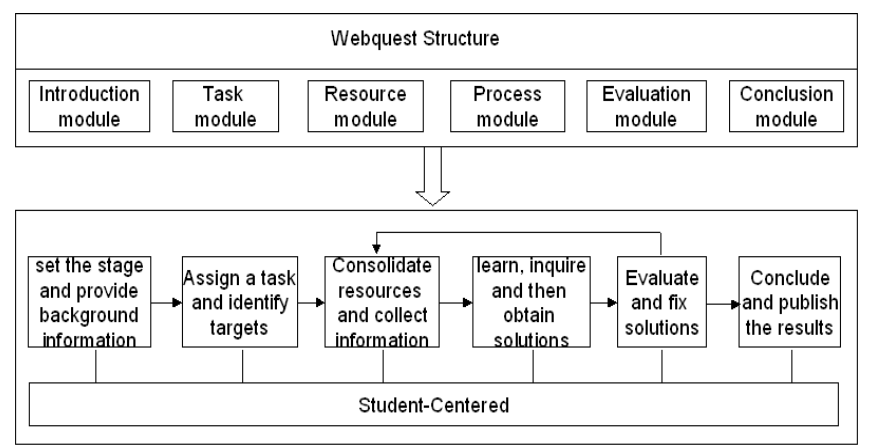

Fig.2. Webquest-based teaching model for network interconnection course

\section{WeBquest-BASED TEACHING Platform FOR NETWORK INTERCONNECTION COURSE}

\section{A. The structure of webquest-based teaching platform for network interconnection curse}

Webquest-based teaching platform for network interconnection course consists of four parts, namely, scenario teaching module, teaching resources module, interactive inquiry platform and scenarios train module, shown as in Figure 3. Teaching Resources consists of two part, they are online resources and resource coordination model. Teaching resources is the web part of the webquest, and the interactive inquiry platform is the quest part of the webquest.

\section{B. Scenario teaching module}

Scenario teaching module consists of two aspects of aims. The first purpose is to make clear to learners what to learn. The second purpose is to enhance the learning interest through a variety of ways. To achieve these two aims, the created scenario should be attractive, the inquiry themes and 
the learner's past experience are relevant, and the learner's future goals are also relevant. Teaching design must enable students to fully understand the reason to inquiry, and create a corresponding learning scenario.

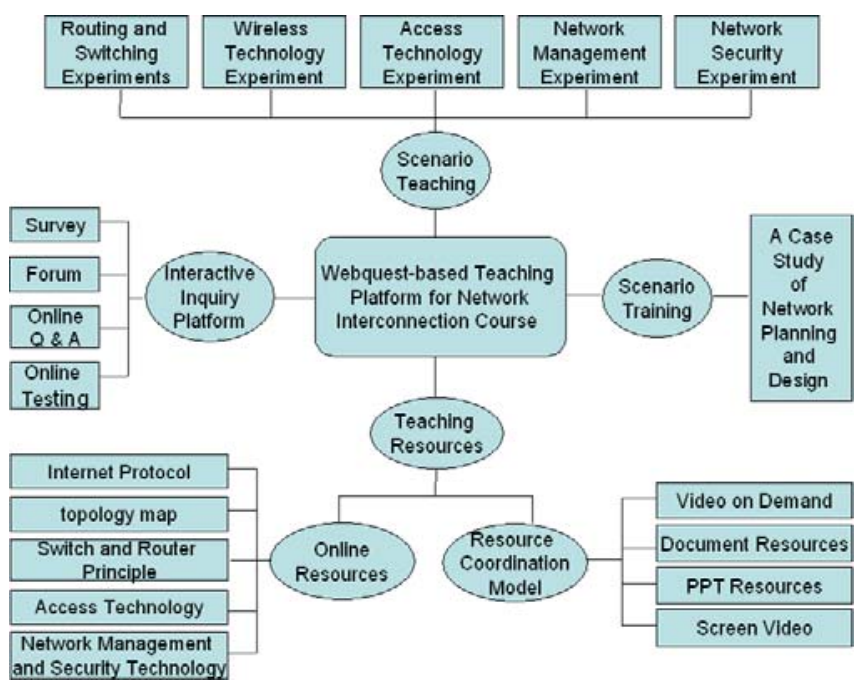

Fig.3. Webquest-based teaching platform for network interconnection course

Network interconnection course has a strong practical, so the real teaching environment is essential. The teaching system for network interconnection course requires not only engineering training scenarios, but also the true perception of knowledge and skills. Vivid vision can effectively stimulate the association, draw knowledge and experience or long-term memory, so that learners can use the relevant knowledge and experience, absorb new knowledge at the base of the original cognitive structure, and to give some meaning of new knowledge.

The experiments of network interconnection course are divided into five categories: routing and switching experiments, wireless technology experiment, access technology experiment, network management and security experiments. Requirements of each type of experiments conducted in a real environment, our school has a special networking experiment room, and installed the corresponding experimental environment that can provide students with on-demand experiment.

\section{Teaching Resources}

Teaching resources can provide some background material, to arouse the learner's existing knowledge and experience, to prepare for the new learning, such as topology map drawn according to the demand, the use of switches and routers, and the principle of Internet protocols and so on.

- Video on demand. Vivid vision can effectively stimulate the association, draw knowledge and experience or long-term memory. Using a small FLV format for streaming media, the server's load is small and more secure. In order to achieve multi-level sharing, video on demand function can publish the list according to teachers, but students can also create their own list.

- Document Resources. Document Resources provide the relevant information and tools for mission and goals, such as information, data, background knowledge, and related websites. Teachers in the selection of resources should play good "Navigator" role, such as information sorting, filtering and classification, and provide students search engine related to issues.

- $\quad$ PPT. PPT resources cover the five major teaching purpose and teaching content of network interconnection course, and describe teaching the steps in detail.

- Screen Video. Screen video screen on the main experiment, such as the basic configuration of the switch, VLAN configuration, routing configuration, NAT configuration, VPN configuration, ACL configuration. Students in the class may be previewing and reviewing the knowledge to learn, and the form of video screen is image and intuitive.

\section{Interactive inquiry platform}

As the complexity of knowledge and the difficulty of solving the problem in some cases, it is necessary for learners to carry out inquiry-based network teaching. In this inquiry-based learning environment, all team members can share ideas and wisdom, namely, the entire study group have completed together the significance construction of knowledge.

In the inquiry process, learners can get the guidance of teachers, while teachers can access student feedback. Cooperation can be in two or more students, through teacher's guidance, meet face to face, or exchange knowledge in the online forum. It's convenient to collaborate. In collaboration and exploration, through the different perspectives on the same comparative analysis of the problem, learners can enhance their abilities, and enrich the understanding of knowledge. Interactive inquiry platform of network interconnection course includes the following features.

- Survey. If teachers want to know the attitude of students to a problem, such as what kind of network configuration experiment is that the students are most interested in, it can be obtained through the questionnaire survey. And survey can help teachers understand the students' evaluations of the course, and found the strengths and weaknesses of teaching process. Content and options can be set by teachers and students are involved in the investigation.

- Forum. Forum is a collaboration tool for many people. The forum can be maintained by many people, in which everyone can express their views, extend or explore a common theme. For example, teachers and students may discuss on stack routing or communication between different VLAN, including configuration steps, the problems occurred during the configuration process and so on. Forum supports community-oriented collaborative writing, and it can help users in a community to share a certain field of knowledge.

- Online Q \& A. Online Q \& A is an interactive teaching module, and the core of this module is the student. It supports students to submit questions online, teachers online to answer. Online Q \& A is a private space between teachers and students. In order to reduce duplication and improve learning efficiency, we designed a "Q \& A Collection". Before asking questions, students added some typical questions into the "Q \& A Collection", and then they can search and browse the contents by knowledge points. 
- Online testing. Test is used to detect the student's mastery degree of the knowledge. The platform can add a variety of different types of questions. When test editing is completed, by clicking the test, students can conduct online testing.

\section{E. Scenario Training - A Case Study of Network Planning and Design}

In network interconnection course, students are required to write a formal network planning and design, and we find a real case of network design. According to the six modules of webquest-based teaching model, the concrete teaching steps are shown in figure 4.

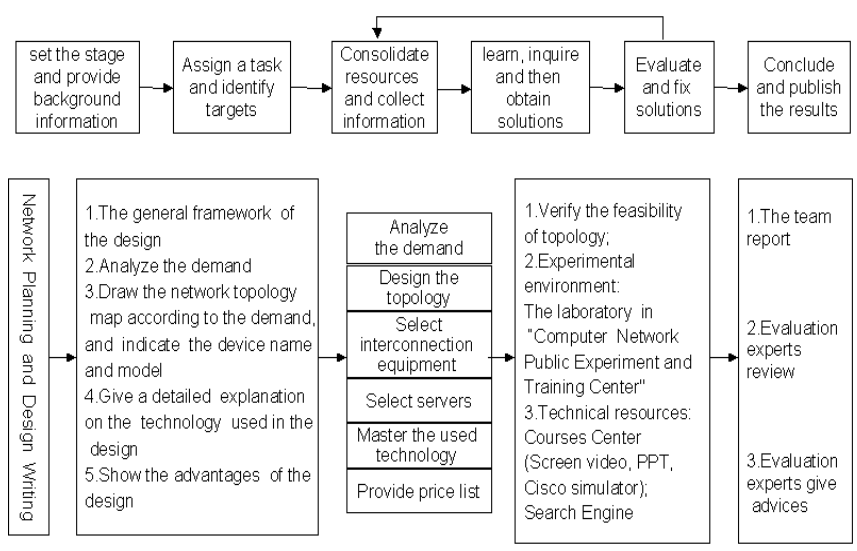

Fig.4. Scenario Training Example Based on Webquest

The solution is designed for a real network project which is a school's network transformation, and it requires students to split into different groups. The first is to enable students to enter the scene, analyze the needs of the school network. Then students will inquiry independently according to their own task. In inquiry independently stage, students can rely on teaching resource library. Students will then share the results of the inquiry and collaborate to learn. The final stage is that the outcome of each group was evaluated.

\section{CONCLUSION}

Webquest greatly expand the extension of learning space. Through webquest teaching platform, students can learn in the classroom first, and then review and practice online; students can choose to learn in the classroom, and also choose to watch a training video online. The biggest advantage of the webquest teaching platform is that students can inquire to learn.

This paper does a survey about webquest-based teaching methods, and the survey number is 32 . The results surveyed in this paper are listed in the TABLE I.

It can be seen from the survey: webquest provides more opportunities for teachers and students to exchange, teachers and students can dialogize in the classroom, they can also discuss in online forums, and post messages in the course chat room. Comparing with pure online learning or simple face to face teaching, blended learning model has more advantages. In a pure online learning, learners will have a strong sense of loneliness because of large distance, it is not conducive to the exchange; in a simple face to face teaching, learners because of limited class time will not have enough time and opportunity to fully consider and exchange.
TABLE I. THE RESULTS OF THE SURVEY

\begin{tabular}{|c|c|}
\hline ITEM & RESULTS \\
\hline $\begin{array}{l}\text { Which one is your } \\
\text { favorite way of } \\
\text { teaching? }\end{array}$ & 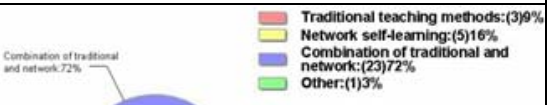 \\
\hline $\begin{array}{l}\text { The frequency of } \\
\text { login webquest- } \\
\text { based teaching } \\
\text { platform for } \\
\text { learning activities. }\end{array}$ & 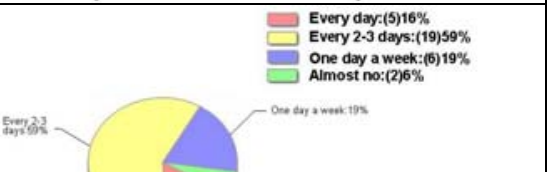 \\
\hline $\begin{array}{l}\text { In the webquest- } \\
\text { based teaching plat- } \\
\text { form, the enrich- } \\
\text { ment situation of } \\
\text { learning content } \\
\text { and learning form. }\end{array}$ & $\begin{array}{l}\text { Large:(21)66\% } \\
\text { Generak:(9)28\% } \\
\text { Small:(2)6\% } \\
\text { Almost no:(0)0\% } \\
\text { - Genowios }\end{array}$ \\
\hline $\begin{array}{l}\text { In the } \\
\text { webquest-based } \\
\text { teaching platform, } \\
\text { the situation of } \\
\text { communicate with } \\
\text { teachers and with } \\
\text { other students. }\end{array}$ & $\begin{array}{l}\text { Mary:(7)22\% } \\
\text { Generat:(17)53\% } \\
\text { Less:(7)22\% } \\
\text { Almost no:(1)3\% } \\
\text { - Lew z2x }\end{array}$ \\
\hline $\begin{array}{l}\text { The situation of } \\
\text { improving learning. }\end{array}$ & $\begin{array}{l}\text { Large:(21)66\% } \\
\text { Generat:(9)28\% } \\
\text { Small:(2)6\% } \\
\text { Almost no:(0)0\% }\end{array}$ \\
\hline $\begin{array}{l}\text { Which one is Your } \\
\text { feeling on the } \\
\text { webquest-based } \\
\text { teaching platform? }\end{array}$ & $\begin{array}{l}\text { Made me more motivated to } \\
\text { leam:(5)16\% } \\
\text { A new way of leaming:(17)53\% } \\
\text { Improve the independent learning } \\
\text { ability:(5)16\% } \\
\text { Face more dimculties:(5)16\% }\end{array}$ \\
\hline
\end{tabular}

- $\quad$ Blended teaching courses can also be easier to invite experts to participate remotely. Visiting experts can be directly involved in the network curriculum activities, these experts may be in a particular area have a higher level, and can give students more inspiration.

- Learners have more opportunities to reflect on what they have learned. Blended learning gives all the possible learning opportunities to the learners, in addition to classroom construction and exchange of knowledge, the learner can re-organize and reflect on what they have learned after-school through the Internet, they can also be shared with other learners to reflect, collaborative construct knowledge.

- Taking advantage of the webquest-based teaching platform, the network interconnection course can give full play to the learner's enthusiasm, initiative and creativity, and greatly improve their ability to innovate, problem solving, communication and social skills. 


\section{ACKNOWLEDGMENT}

This work was supported by Shanghai “Computer Science and Technology” Bachelor Education Platform under Grant No. GD2C0206.

\section{REFERENCES}

[1] FANG Peng, GAO Yao. Research on Cultivating Innovation-type Engineering Talents. Journal of Technology College Education.2008.3(27).
[2] LI LinRui. Webquest Application in Higher Education[J]. Chifeng College Journal: Natural Science. 2009,25(8).

[3] ZHANG Minsheng, SHI Hui. The Exploration and Research on New Model of Classroom Teaching Supported by Information Technology. China Educational Technology. 2008(9).

[4] Zhang Hangjin. Towards blended learning: Educational technology to improve and assess teaching and learning. University of California, Santa Barbara.Computer Science.2009.

[5] Bernie Dodge. Some Thoughts About Webquest [DB/OL].http://Webquest.sdsu.edu/about Webquest.html.. 